\title{
Original tumour suppressor gene polycystic kidney and hepatic disease 1-like 1 is associated with thyroid cancer cell progression
}

\author{
CHEN ZHENG*, RUIDA QUAN*, ER-JIE XIA, ADHEESH BHANDARI and XIAOHUA ZHANG \\ Department of Thyroid and Breast Surgery, The First Affiliated Hospital of Wenzhou Medical University, \\ Wenzhou, Zhejiang 325000, P.R. China
}

Received January 12, 2019; Accepted June 13, 2019

DOI: $10.3892 /$ ol.2019.10632

\begin{abstract}
In recent decades, thyroid cancer (TC) has become one of the most common endocrine malignancies. Next-generation sequencing of paired TC and adjacent healthy thyroid tissues demonstrated that polycystic kidney and hepatic disease 1-like 1 (PKHD1L1) may serve as a tumour suppressor gene in thyroid cancer. However, the function of PKHD1L1 in thyroid cancer is still unknown. To validate the results of whole-transcriptome resequencing, the expression levels of PKHD1L1 were evaluated in 58 pairs of papillary thyroid cancer (PTC) tissue samples and three thyroid cancer cell lines. In addition, The Cancer Genome Atlas (TCGA) data were used to analyse the relationship between PKHD1L1 and patient clinicopathological features. Cell Counting Kit-8, colony formation, migration and invasion assays were performed to assess the effects of PKHD1L1 knockdown in three TC cell lines. PKHD1L1 expression was significantly lower in thyroid carcinoma compared with that in matched normal tissue, and this result was consistent with that in TCGA cohort. TCGA data demonstrated that PKHD1L1 downregulation was associated with a number of aggressive clinicopathological features, such as histological type, lymph node metastasis (LNM), distant metastasis, tumour size and clinical stage. Logistic regression analysis of data from patients with PTC revealed that PKHD1L1 expression, histological type, age and tumour size were independent high-risk factors for LNM. The PKHD1L1 biological function was investigated in the three TC cell lines: TPC-1, KTC1 and BCPAP. A loss of function experiment demonstrated that PKHD1L1 knockdown promoted cell proliferation, colony formation and cell invasion
\end{abstract}

Correspondence to: Professor Xiaohua Zhang, Department of Thyroid and Breast Surgery, The First Affiliated Hospital of Wenzhou Medical University, Nan Bai Xiang, Wenzhou, Zhejiang 325000, P.R. China

E-mail: oncology_zhang@outlook.com

*Contributed equally

Key words: polycystic kidney and hepatic disease 1-like 1, papillary thyroid carcinoma, proliferation, metastasis in TC cell lines. In conclusion, PKHD1L1 may be a tumour suppressor gene associated with PC, and may be a potential therapeutic target in the future.

\section{Introduction}

Thyroid cancer (TC) is one of the most common malignant tumours of the endocrine system (1). In the USA, 53,990 new cases were estimated in 2018 (2). Similarly, the number of newly diagnosed cases and TC-associated mortalities in China were estimated at $\sim 90,000$ and 6,800, respectively (3). TC has been predicted to surpass colorectal cancer and become the fourth most common cancer in 2030 worldwide $(4,5)$. Papillary thyroid cancer (PTC), which comprises diverse biological subtypes, accounts for $\sim 80 \%$ of TC cases (6). The incidence of PTC is high, but it has positive clinical outcomes and a high 5-year survival rate compared with other malignant tumours (7). Following surgery or radioactive iodine therapy, patients with PTC exhibit satisfactory prognoses, as well as an overall 10-year survival rate of $90 \%$ (8).

Although PTC is associated with relatively good prognosis and a high cure rate, metastasis and recurrence are common following routine treatment; of all patients with PTC, $10-15 \%$ experience recurrence and distant metastasis (9). In addition, previous studies have reported that gene mutations, such as the stimulation of oncogenes and the silencing of tumour suppressor genes, are the most common initiators of tumourigenesis and progression of PTC $(10,11)$. Therefore, it is important to identify the molecular markers and potential therapeutic targets for PTC.

Genomics is a useful tool for the exploration of gene mutations. Over the past two decades, several studies have reported that certain gene mutations result in tumourigenesis and TC progression. For instance, B-type Raf kinase V600E is a common gene mutation that can accelerate thyroid tumourigenesis by abnormally triggering mitogen-activated protein kinase (12). In addition, Ret proto-oncogene (RET) somatic rearrangements RET/PTC1 and RET/PTC3 can sustain the activation of the RET tyrosine kinase domain; stimulation of the RET tyrosine kinase domain induces changes in PTC cell cytoplasm $(13,14)$. Mutations in other genes, such as PTEN (15), p53 (16) and telomerase reverse transcriptase (17), have been demonstrated to serve significant roles in tumourigenesis and progression of TC. Despite the progress in thyroid 
cancer research over the past decades, the exact mechanisms of PTC development and progression remain unknown.

To explore the occurrence and progression of $\mathrm{TC}$, whole-transcriptome resequencing of 19 pairs of primary PTC and adjacent healthy tissue samples was performed in our previous unpublished study. A series of comprehensive analyses revealed that the PKHD1L1 gene was highly associated with PTC, especially during tumourigenesis. PKHD1L1 was initially identified as a mouse gene (18), but the function of the gene was not well understood. A further study reported that PKHD1L1 encodes fibrocystin-L, which serves a crucial role in cellular immunity (19). In addition, a PKHD1L1 mutation may cause autosomal recessive polycystic kidney disease (ARPKD) (20). Erdman et al demonstrated that the PKHD1L1 genotype may be a relevant factor in male longevity (21). Although the gene has been discovered for a long time the exact functions of PKHD1L1 in humans remain poorly understood.

\section{Materials and methods}

Patients and samples. For the validated cohort, 52 fresh PTC tissue samples and paired adjacent $(\sim 10 \mathrm{~mm}$ away from the tumour) normal tissue samples were collected surgically from patients with PTC treated at The First Affiliated Hospital of Wenzhou Medical University between January 2014 and January 2018. None of the patients underwent chemotherapy or radiotherapy prior to the surgery. The mean age of the patients with PTC was 46.9 years (range, 22-75 years). $85 \%$ of the patients were female. Following tissue sample were collection, liquid nitrogen was used to immediately freeze the samples, and all samples were stored at $-80^{\circ} \mathrm{C}$ for further experiments. The histological diagnoses were confirmed by retrospective review of the cases, and the tumour samples were assessed by two senior pathologists.

RNA extraction and reverse transcription-quantitative $(R T-q)$ $P C R$. Total RNA was isolated from the tissue samples using TRIzol ${ }^{\circledR}$ reagent (Thermo Fisher Scientific, Inc.) according to the manufacturer's protocol. For assessment of RNA quality and quantity, the A260/A280 ratio (1.8-2.0) and spectrophotometry values were used, respectively, as detected using a NanoDrop $^{\text {TM }} 2000$ (Thermo Fisher Scientific, Inc.). The total RNA was reverse transcribed into cDNA using the ReverTra Ace ${ }^{\circledR}$ qPCR RT kit (Toyobo Life Science) at $16^{\circ} \mathrm{C}$ for $5 \mathrm{~min}$, $42^{\circ} \mathrm{C}$ for $30 \mathrm{~min}$ and $98^{\circ} \mathrm{C}$ for $5 \mathrm{~min}$. The resulting cDNA samples were stored at $-80^{\circ} \mathrm{C}$. The relative expression levels of PKHD1L1 were detected using the ABI PRISM 7500 Sequence Detection system (Thermo Fisher Scientific, Inc.) with One Step SYBR ${ }^{\circledR}$ PrimeScript $^{\mathrm{TM}}$ PLUS and the RT $\square$ RNA PCR kit (Takara Bio, Inc.) according to the manufacturer's protocol. RT-qPCR was performed in triplicate. The thermocycling conditions were: $95^{\circ} \mathrm{C}$ for $2 \mathrm{~min}$, followed by 40 cycles of $95^{\circ} \mathrm{C}$ for $15 \mathrm{sec}$ and $60^{\circ} \mathrm{C}$ for $60 \mathrm{sec}$, and a final step of $72^{\circ} \mathrm{C}$ for $5 \mathrm{~min}$. The relative expression of mRNA was calculated using the $2^{-\Delta \Delta \mathrm{Cq}}$ method (22). GAPDH expression was used as an internal control. The primer sequences were as follows: PKHD1L1 forward, 5'-TGTGAAGTGAGTGTG GTTAA-3'; and PKHD1L1 reverse, 5'-GCAGTGATGAGT GGAGTC-3'; GAPDH forward, 5'-GGTCGGAGTCAACGG
ATTTG-3'; and GAPDH reverse, 5'-ATGAGCCCCAGCCTT CTCCAT-3'.

The Cancer Genome Atlas (TCGA) data. To explore the prognostic value of PKHD1L1 in TC, PTC RNA-seq data for PKHD1L1 and corresponding patient clinical data, comprising the PKHD1L1 expression data and follow-up information, were obtained from TCGA database (https://tcgadata.nci. nih.gov/tcga). In total, data from 502 PTC tissue samples and 58 normal thyroid tissue samples were analysed.

Cell lines and cell culture. TPC-1 and BCPAP TC cell lines were kindly supplied by Professor Ming-Zhao Xing of Johns Hopkins University School of Medicine. KTC-1 and HTORI3 cell lines were purchased from the Stem Cell Bank of the Chinese Academy of Sciences. The use of the cell lines was approved by the Ethics Committee of The First Affiliated Hospital of Wenzhou Medical University. No cell line authentication was performed by the authors prior to the study. The cells were cultured in RPMI-1640 medium (Invitrogen; Thermo Fisher Scientific, Inc.) supplemented with $10 \%$ foetal bovine serum (FBS; Invitrogen; Thermo Fisher Scientific, Inc.) in a $37^{\circ} \mathrm{C}$ humidified incubator with $5 \% \mathrm{CO}_{2}$.

RNA interference. PKHD1L1 small interfering (si)RNA and negative control siRNA (si-NC) were provided by Shanghai GenePharma Co., Ltd. A total of three siRNAs were designed to investigate the function of PKHD1L1; however, no statistically significantdifferences were observed between them in the subsequent experiments. The effective sequence for the PKHD1L1 siRNA was as follows: Sense, GCUGAUGGCAUAAACAUA ATT; antisense, UUAUGUUUAUGCCAUCAGCTTTPC-1 ( $4.5 \times 10^{5}$ cells/well), KTC1 $\left(8 \times 10^{5}\right.$ cells/well) and BCPAP cells $\left(7 \times 10^{5}\right.$ cells/well) were digested with trypsin-EDTA $(0.05 \%$; Thermo Fisher Scientific, Inc.) at $37^{\circ} \mathrm{C}$ for $2 \mathrm{~min}$, plated onto 6-well plates, and incubated for at least $24 \mathrm{~h}$ in RPMI-1640 medium. Following incubation, siRNA transfection was performed using Lipofectamine ${ }^{\circledR}$ RNAiMAX (Invitrogen; Thermo Fisher Scientific, Inc.) according to the manufacturer's protocol (at $37^{\circ} \mathrm{C}$ for $6-8 \mathrm{~h}$ ). The final siRNA concentration was $100 \mathrm{nM}$ for TPC-1, $50 \mathrm{nM}$ for BCPAP and $75 \mathrm{nM}$ for KTC-1. The analysis of RNA expression was performed $48 \mathrm{~h}$ later. The experiments were conducted in triplicate.

Cell proliferation assay. Cell Counting Kit-8 (CCK-8; Beyotime Institute of Biotechnology) was used according to the manufacturer's protocol to observe the proliferative ability of the cells. Following transfection, TPC-1, KTC1 and BCPAP cells were plated into 96 -well plates at a density of $1.5 \times 10^{3}$ cells/well. On days $1,2,3$ and 4, CCK- 8 solution $(10 \mu \mathrm{l})$ was added to each well and incubated for $2.5 \mathrm{~h}$ at $37^{\circ} \mathrm{C}$. Absorbance levels were detected at $450 \mathrm{~nm}$ (OD450) using a SpectraMax M5 (Molecular Devices, LLC). For every group, data from five wells were collected for analysis. All the assays were performed in triplicate.

Colony-formation assay. The three cell lines were seeded into six-well plates at a density of $1.5 \times 10^{3}$ cells/well for TPC-1 and KTC- 1 and $2 \times 10^{3}$ cells/well for BCPAP. Cells were incubated in $5 \% \mathrm{CO}_{2}$ at $37^{\circ} \mathrm{C}$ for 8-14 days. When 50-70 cells 
in one colony-forming unit were observed, via an inverted light microscopy (magnification, x10), 4\% paraformaldehyde (Sigma-Aldrich; Merck KGaA) was used to fix cells at $27^{\circ} \mathrm{C}$ for $30 \mathrm{~min}$. Subsequently, cells were stained with $0.01 \%$ crystal violet at $27^{\circ} \mathrm{C}$ for $30 \mathrm{~min}$. All assays were performed in triplicate.

Migration and invasion assays. For the migration assay, Transwell chambers (Costar; Corning, Inc.) were used. Transfected TC cells $\left(3 \times 10^{5}\right.$ cells $/ 0.3 \mathrm{ml}$ medium for TPC-1 and KTC- 1 cells and $3.5 \times 10^{5}$ cells $/ 0.3 \mathrm{ml}$ medium for BCPAP cells) were seeded into the upper chamber. A total of $0.6 \mathrm{ml}$ RPMI-1640 medium supplemented with $20 \%$ FBS was put in the lower chamber. Following 24-h incubation in $5 \% \mathrm{CO}_{2}$ at $37^{\circ} \mathrm{C}$, a cotton swab was used to remove the cells that had not migrated to the lower surface of the well. The cells on the lower surface were fixed with $4 \%$ paraformaldehyde and stained with $0.4 \%$ crystal violet for (both $27^{\circ} \mathrm{C}$, for $15 \mathrm{~min}$ ). Images were captured at five random fields of view under a light microscope (mgnification, x40) for further analysis.

BioCoat $^{\mathrm{TM}}$ Matrigel Invasion Chambers (Corning, Inc.) were left to equilibrate to room temperature for $30 \mathrm{~min}$, and were used for the invasion assay following the protocol described for the migration assay.

Statistical analysis. Statistical data analyses were performed using SPSS 23.0 software (IBM Corp.). GraphPad Prism version 6.01 (GraphPad Software, Inc.) was used to plot the data. Data with a normal distribution were expressed as the mean \pm standard deviation. In the validated cohort, the differences between the tumour and normal groups were estimated by paired Student's t-test (two-tailed). The differences in characteristics between three groups were examined by ANOVA, and the least significant difference test was used for multiple comparisons. The differences between the treated and untreated cells were analysed by unpaired Student's t-test (two-tailed). In the TCGA cohort and validated cohort, the associations between PKHD1L1 expression and clinicopathological features were analysed by the $\chi^{2}$ test. In the TCGA cohort, the association between PKHD1L1 expression and lymph node metastasis (LNM) was analysed by univariate and multivariate logistic regression analyses. $\mathrm{P}<0.05$ was considered to indicate a statistically significant difference.

\section{Results}

PKHDIL1 is significantly downregulated in PTC. To investigate the function of PKHD1L1 in PTC, TCGA data were used to confirm the expression level of PKHD1L1. PKHD1L1 was significantly downregulated in TCGA cohort $(\mathrm{P}<0.001$; Fig. 1). Subsequently, PKHD1L1 mRNA expression levels were analysed in the validated PTC cohort by RT-qPCR. The results demonstrated that PKHD1L1 was significantly downregulated in the tumour samples compared with adjacent normal tissues $(\mathrm{P}<0.001$; Fig. 2). Therefore, these data suggest that PKHD1L1 may act as an anti-tumour gene in PTC.

PKHDIL1 expression is associated with the clinicopathological features of patients with PTC. To facilitate in-depth investigation of PKHD1L1 in PTC, the association between

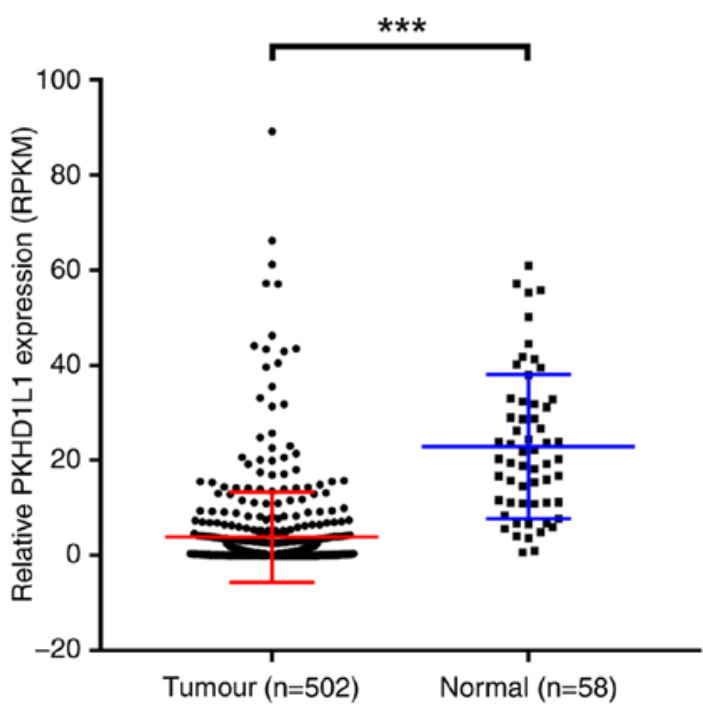

Figure 1. mRNA expression of PKHD1L1 in TCGA cohort. PKHD1L1 expression was significantly downregulated in 502 PTC samples compared with 58 adjacent noncancerous thyroid samples in TCGA cohort. ${ }^{* * * *} \mathrm{P}<0.001$. PKHD1L1, polycystic kidney and hepatic disease 1-like 1; PTC, papillary thyroid carcinoma; TCGA, The Cancer Genome Atlas; RPKM, reads per kilobase per million mapped reads.

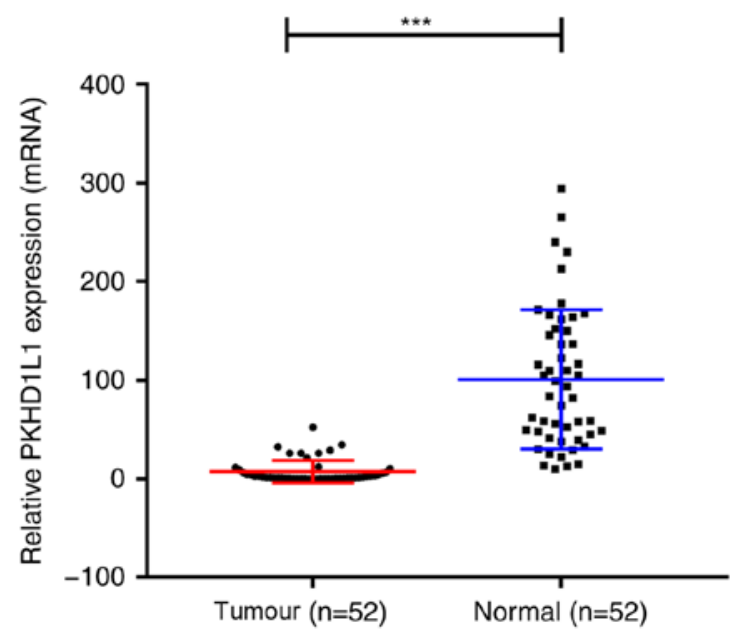

Figure 2. mRNA expression of PKHD1L1 in the validated cohort. PKHD1L1 expression was significantly downregulated in PTC tissues compared with adjacent noncancerous thyroid tissues $(\mathrm{N}=52) .{ }^{* * *} \mathrm{P}<0.001$. PKHD1L1, polycystic kidney and hepatic disease 1-like 1; PTC, papillary thyroid carcinoma.

PKHD1L1 and clinical features of patients with PTC was analysed. Based on TCGA cohort, 502 patients were divided into low and high PKHD1L1 expression groups based on the median reads per kilobase of transcript per million value of 0.4238 ( $n=251)$. The results demonstrated that low PKHD1L1 expression was associated with LNM $(\mathrm{P}<0.001)$, tumour size $(\mathrm{P}=0.003)$, disease stage $(\mathrm{P}<0.001)$ [based on the 7 th edition of the American Joint Committee on Cancer Staging Manual (23)] and distant metastasis $(\mathrm{P}=0.018)$ (Table I). No significant associations were identified between PKHD1L1 expression and age, sex, histological type, or multifocality. In the validated cohort, low PKHD1L1 expression was associated with LNM $(\mathrm{P}=0.035)$ and tumour size $(\mathrm{P}=0.039)$ but not with disease stage $(\mathrm{P}=0.614)$, as demonstrated in Table II. 
Table I. Association between PKHD1L1 expression and clinicopathological features of patients with papillary thyroid carcinoma in The Cancer Genome Atlas cohort.

\begin{tabular}{|c|c|c|c|c|}
\hline Clinicopathological feature & Low expression $(n=251)$ & High expression $(n=251)$ & $\chi^{2}$ & P-value \\
\hline Sex & & & 0.253 & 0.615 \\
\hline Female & 186 & 181 & & \\
\hline Male & 65 & 70 & & \\
\hline Age, years & $48.0 \pm 16.2^{\mathrm{a}}$ & $46.7 \pm 15.5^{\mathrm{a}}$ & 0.800 & 0.371 \\
\hline$\leq 45$ & 113 & 123 & & \\
\hline$>45$ & 138 & 128 & & \\
\hline Histological type & & & 2.473 & 0.116 \\
\hline Classical & 186 & 170 & & \\
\hline Other types & 65 & 81 & & \\
\hline Multi-nodularity & & & 0.392 & 0.531 \\
\hline Yes & 110 & 116 & & \\
\hline No & 137 & 129 & & \\
\hline Tumour size, mm & & & 8.565 & $0.003^{\mathrm{b}}$ \\
\hline$\geq 20$ & 57 & 86 & & \\
\hline$<20$ & 194 & 163 & & \\
\hline Lymph-node metastasis & & & 14.369 & $<0.001^{\mathrm{b}}$ \\
\hline Yes & 136 & 87 & & \\
\hline No & 99 & 130 & & \\
\hline Distant metastasis & & & 5.556 & $0.018^{\mathrm{b}}$ \\
\hline Yes & 12 & 3 & & \\
\hline No & 239 & 248 & & \\
\hline Disease stage $^{c}$ & & & 12.309 & $<0.001^{\mathrm{b}}$ \\
\hline I+II & 148 & 185 & & \\
\hline III+IV & 102 & 65 & & \\
\hline
\end{tabular}

${ }^{\mathrm{a}}$ Mean \pm SD. ${ }^{\mathrm{b}} \mathrm{P}<0.05 .{ }^{\mathrm{c}}$ Based on the 7 th edition of the American Joint Committee on Cancer Staging Manual. PKHD1L1, polycystic kidney and hepatic disease 1-like 1.

Low PKHDIL1 expression increases the risk of LNM in patients with PTC. Logistic regression analysis was used to further assess the association between PKHD1L1 expression and LNM. In TCGA cohort, PKHD1L1 expression [odds ratio (OR), 0.487; 95\% confidence interval (CI), 0.335-0.709; $\mathrm{P}<0.001$ ], age (OR, 0.62; 95\% CI, 0.427-0.899; $\mathrm{P}=0.012)$, histological subtype (OR, 2.383; 95\% CI, 1.544-3.680; $\mathrm{P}<0.001)$, tumour size (OR, 2.525; 95\% CI, 1.625-3.858; $\mathrm{P}<0.001)$ and sex (OR, 1.551; 95\% CI, 1.022-2.353; $\mathrm{P}=0.039)$ were significant predictors of LNM (Table III). Multivariate logistic regression analysis confirmed that PKHD1L1 expression (OR, 0.555; 95\% CI, 0.356-0.866; $\mathrm{P}=0.009)$, histological subtype (OR, 2.84; 95\% CI, 1.72-4.692; $\mathrm{P}<0.001)$ and age $(\mathrm{OR}, 0.03$; 95\% CI, 0.009-0.1; $\mathrm{P}<0.001)$ were significant predictors of LNM (Table IV). Therefore, low expression of PKHD1L1 may increase LNM risk in patients with PTC.

Knockdown of PKHDIL1 promotes TC cell proliferation. To confirm the function of PKHD1L1 in TC, PKHD1L1 expression levels were assessed in three TC cell lines (TPC-1, KTC1 and BCPAP) and normal thyroid cells (HTORI3) by RT-qPCR. Expression of PKHD1L1 was higher in HTORI3 compared with that in TPC-1, KTC-1 and BCPAP (Fig. 3A). As PKHD1L1 expression is commonly downregulated in PTC, this gene may serve an important function in tumourigenesis and progression of PTC.

A total of three siRNAs were designed to investigate the function of PKHD1L1, and one effective siRNA was selected to downregulate the expression level of PKHD1L1 in the TC cell lines. RT-qPCR was used to detect PKHD1L1 expression levels in transfected cells (Fig. 3B). CCK-8 assay demonstrated that knockdown of PKHD1L1 promoted cell proliferation in the three TC cell lines compared with the respective negative controls $(\mathrm{P}<0.01$; Fig. 3C). Cells transfected with PKHD1L1 siRNA exhibited increased proliferative capacity, which approached statistical significance at 3 or 4 days of cell culture. In addition, PKHD1L1 knockdown promoted TC cell colony formation compared with the control group ( $\mathrm{P}<0.001$; Fig. 3D).

Knockdown of PKHDIL1 regulates the migration and invasion of TC cell lines in vitro. Based on the results of the clinicopathological feature analysis and cell proliferation and colony formation experiments, the role of PKHD1L1 in the migratory and invasive capacities of the three types of TC cell lines was further 
Table II. Association between PKHD1L1 expression and clinicopathological features of patients with papillary thyroid carcinoma in the validated cohort.

\begin{tabular}{|c|c|c|c|c|}
\hline Clinicopathological features & Low expression $(\mathrm{N}=26)$ & High expression $(\mathrm{N}=26)$ & $\chi^{2}$ & P-value \\
\hline Sex & & & & 1.000 \\
\hline Female & 22 & 22 & & \\
\hline Male & 4 & 4 & & \\
\hline Age, years & $47.5 \pm 14.2^{\mathrm{a}}$ & $46.4 \pm 14.6^{\mathrm{a}}$ & 0.310 & 0.578 \\
\hline$\leq 45$ & 13 & 11 & & \\
\hline$>45$ & 13 & 15 & & \\
\hline Histological type & & & & 1.000 \\
\hline Classical & 21 & 22 & & \\
\hline Other types & 5 & 4 & & \\
\hline Multi-nodularity & & & 0.077 & 0.781 \\
\hline Yes & 14 & 13 & & \\
\hline No & 12 & 13 & & \\
\hline Tumour size, mm & & & 4.282 & $0.039^{\mathrm{b}}$ \\
\hline$\geq 20$ & 21 & 14 & & \\
\hline$<20$ & 5 & 12 & & \\
\hline Lymph-node metastasis & & & 4.475 & $0.035^{\mathrm{b}}$ \\
\hline Yes & 24 & 18 & & \\
\hline No & 2 & 8 & & \\
\hline Distant metastasis & & & & 1.000 \\
\hline Yes & 2 & 1 & & \\
\hline No & 24 & 25 & & \\
\hline Disease stage $^{c}$ & & & & 0.614 \\
\hline $\mathrm{I}+\mathrm{II}$ & 22 & 20 & & \\
\hline III+IV & 3 & 1 & & \\
\hline
\end{tabular}

${ }^{\mathrm{a}}$ Mean $\pm \mathrm{SD} .{ }^{\mathrm{b}} \mathrm{P}<0.05 .{ }^{\mathrm{c}}$ Based on the 7 th edition of the American Joint Committee on Cancer Staging Manual. PKHD1L1, polycystic kidney and hepatic disease 1-like 1 .

investigated. The migratory ability of PKHD1L1-knockdown cells was increased in the TC cell lines compared with that in the control cells. The invasive capacity of the PKHD1L1-knockdown cells was significantly higher compared with that of the corresponding control cells (Fig. 4). Thus, PKHD1L1 may serve a crucial role in the migratory and invasive capacities of the TC cell lines.

\section{Discussion}

In recent decades, thyroid cancer (TC) has become one of the most common endocrine malignancies, as the number of annual TC cases has increased by $4 \%$ globally since 2010 (5). Although PTC has a positive prognosis (8), capsular invasion, LNM and distant metastasis in some patients with PTC are a non-negligible problem. A large study has demonstrated that the incidence of capsular invasion and LNM is $20-50 \%(24,25)$. These events may also lead to disease recurrence (26) and cancer-specific mortality (27). In addition, $20-50 \%$ of patients diagnosed with PTC experience LNM (28), and more than one-third of them have clinically detected lymph node involvement on initial presentation (29). Despite the advances in medical science, the potential mechanism of such pathogenesis is still not sufficiently confirmed, which indicates a major research deficiency in TC. To avoid unnecessary lymph node dissection and to further understand LNM in PTC, molecular markers that effectively predict TC progression and are potential PTC targets need to be identified.

A high-throughput sequencing aiming to explore potential molecular biomarkers that could predict PTC progression or assess the risk for PTC was conducted in our previous unpublished study. A total of 19 pairs of PTC tumour samples and adjacent normal tissue samples were subjected to this technique, and the results demonstrated that PKHD1L1 expression levels were lower in PTC tumour tissue compared with adjacent normal thyroid tissue. This result suggested that PKHD1L1 may be a tumour suppressor in PTC.

PKHD1L1 was initially reported as a mouse gene $(18,19)$, but it was subsequently demonstrated that it encodes a putative receptor protein, and that its mutation may cause ARPKD (19). Low PKHD1L1 expression is detected in many primary immune cell subtypes, but it is specifically upregulated and serves as an initiator of activation signals in T lymphocytes (20). In a Hispanic population, the PKHD1L1 gene is also associated with the pathophysiology of childhood obesity (30). A previous 
Table III. Univariate logistic regression analysis for the risk factors of lymph node metastasis in patients with papillary thyroid carcinoma.

\begin{tabular}{llcr}
\hline Factor & OR & $95 \%$ CI & P-value \\
\hline PKHD1L1 expression (high vs. low) & 0.487 & $0.335-0.709$ & $<0.001^{\mathrm{a}}$ \\
Histological type & 2.383 & $1.544-3.680$ & $<0.001^{\mathrm{a}}$ \\
Tumour size, mm $(\geq 20$ vs. $<20)$ & 2.525 & $1.652-3.858$ & $<0.001^{\mathrm{a}}$ \\
Multi-nodularity & 1.446 & $0.994-2.103$ & 0.054 \\
Age, years $(\leq 45$ vs. $>45)$ & 0.62 & $0.427-0.899$ & $0.012^{\mathrm{a}}$ \\
Sex (male vs. female) & 1.551 & $1.022-2.353$ & $0.039^{\mathrm{a}}$ \\
Disease stage & 3.493 & $2.316-5.258$ & $<0.001^{\mathrm{a}}$ \\
\hline
\end{tabular}

${ }^{\mathrm{a}} \mathrm{P}<0.05$. ${ }^{\mathrm{b}}$ Based on the 7th edition of the American Joint Committee on Cancer Staging Manual. PKHD1L1, polycystic kidney and hepatic disease 1-like 1; OR, odds ratio; CI, confidence interval.

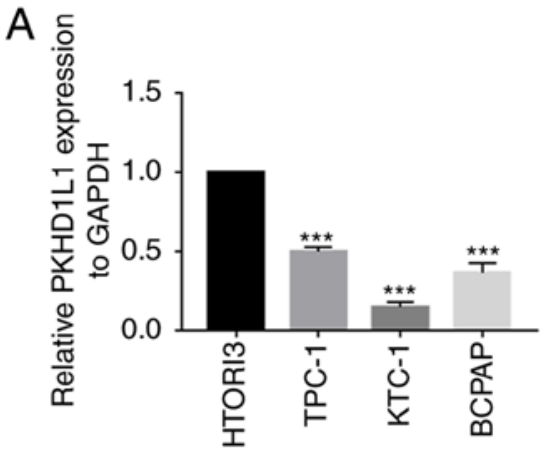

$$
\text { C }
$$

C
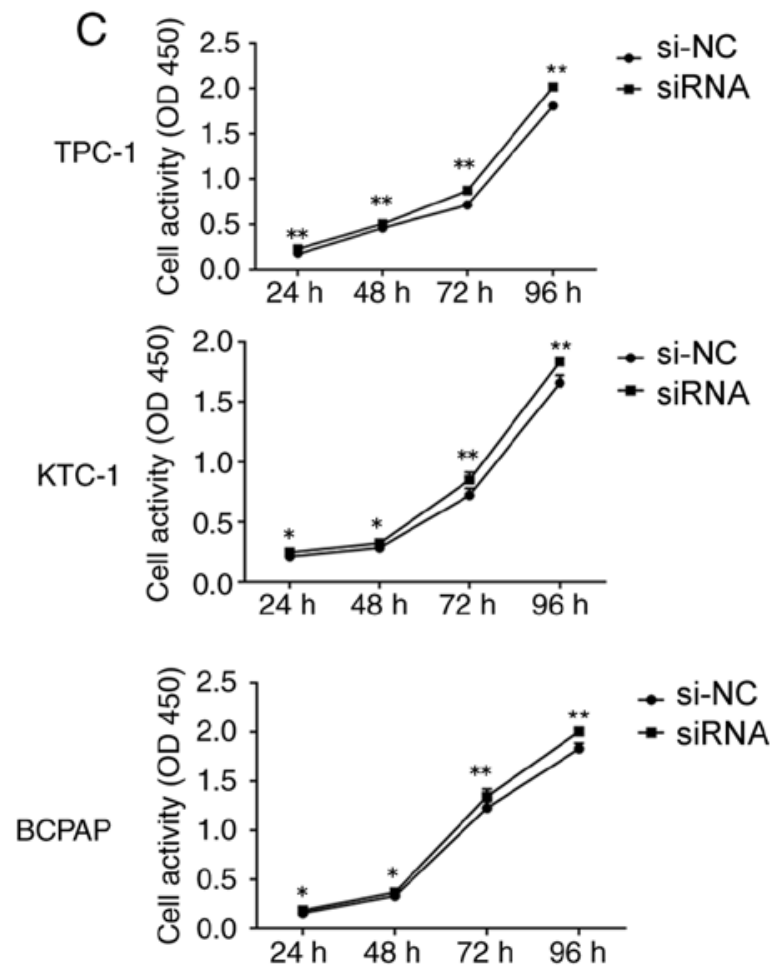

B

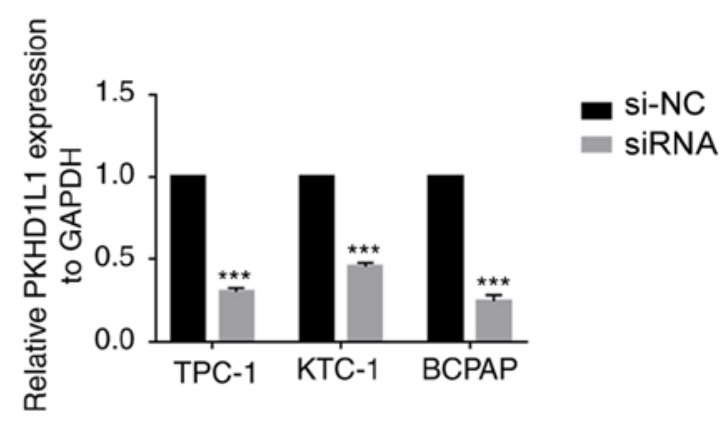

D

TPC-1
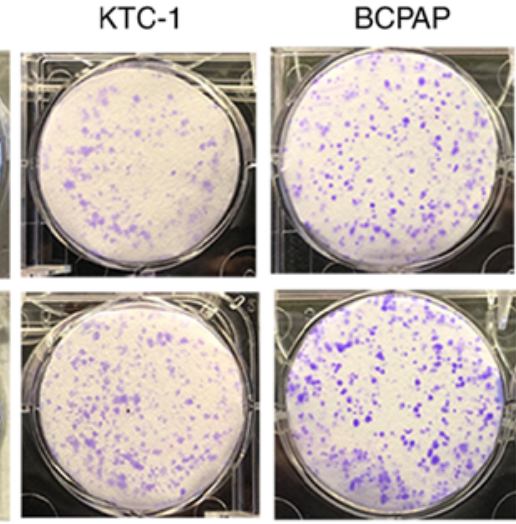

E

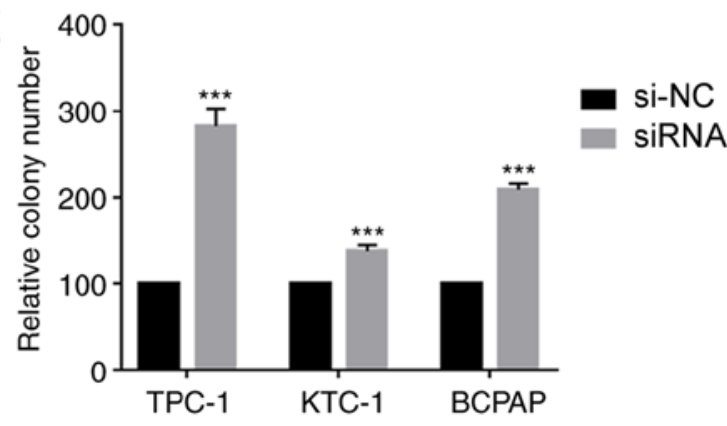

Figure 3. Downregulated expression of PKHD1L1 promotes cell proliferation in TC cell lines. (A) The relative expression of PKHD1L1 in thyroid cells was examined by reverse transcription-quantitative PCR. PKHD1L1 expression levels were higher in the normal thyroid cell line HTORI3 compared with that in the TC cell lines TPC-1, KTC-1 and BCPAP. (B) Compared with the corresponding si-NC groups, the expression levels of PKHD1L1 in the siRNA groups were lower. (C) TPC-1, KTC-1 and BCPAP cell lines transfected with siRNA or si-NC were cultured in 96-well plates for 4 days, and cell proliferation was measured daily using CCK-8. (D) Colony formation of siRNA- and si-NC-transfected TC cells following 8-14 days of incubation. (E) Histogram of colony formation in siRNA- and si-NC-transfected TC cells. siRNA significantly promoted cell proliferation in the thyroid cells. ${ }^{*} \mathrm{P}<0.05,{ }^{* *} \mathrm{P}<0.01$ and ${ }^{* * * *} \mathrm{P}<0.001$ vs. si-NC. PKHD1L1, polycystic kidney and hepatic disease 1-like 1; TC, thyroid cancer; OD450, optical density at $450 \mathrm{~nm}$. 
Table IV. Multivariate logistic regression analysis for risk factors of lymph node metastasis in patients with papillary thyroid carcinoma.

\begin{tabular}{llcr}
\hline Factor & OR & $95 \%$ CI & P-value \\
\hline PKHD1L1 expression (high vs. low) & 0.555 & $0.356-0.866$ & $0.009^{\mathrm{a}}$ \\
Histological type & 2.84 & $1.72-4.692$ & $<0.001^{\mathrm{a}}$ \\
Tumour size, mm $(\geq 20$ vs. $<20)$ & 1.299 & $0.762-2.213$ & 0.336 \\
Age, years $(\leq 45$ vs. $>45)$ & 0.03 & $0.009-0.1$ & $<0.001^{\mathrm{a}}$ \\
Sex (male vs. female) & 1.518 & $0.916-2.514$ & 0.105 \\
Disease stage & 55.634 & $16.371-189.066$ & $<0.001^{\mathrm{a}}$
\end{tabular}

${ }^{\mathrm{a} P}<0.05$. ${ }^{\mathrm{b} B a s e d}$ on the 7 th edition of the American Joint Committee on Cancer Staging Manual. PKHD1L1, polycystic kidney and hepatic disease 1-like 1; OR, odds ratio; CI, confidence interval.

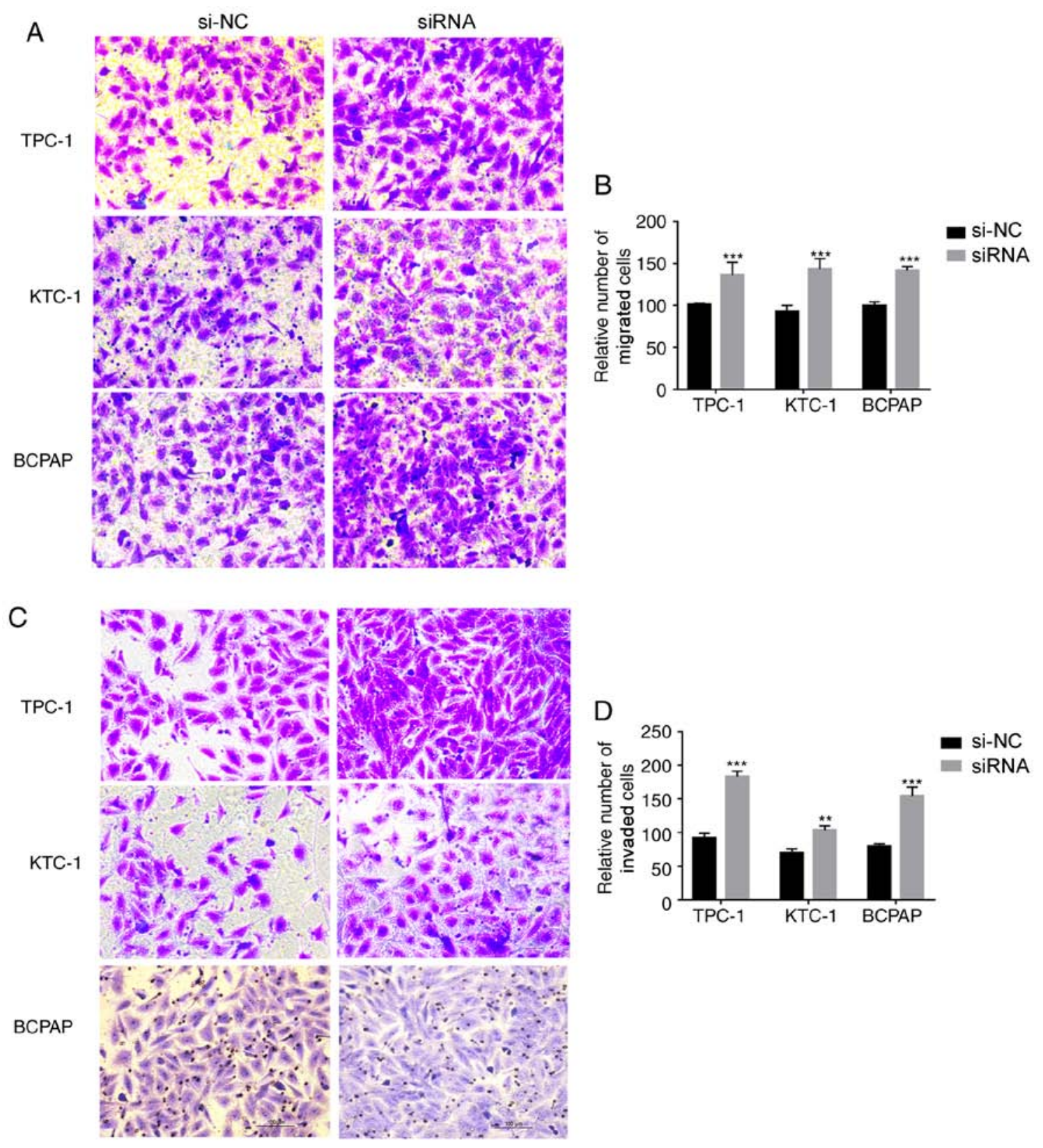

Figure 4. Knockdown of PKHD1L1 in TPC-1, KTC-1 and BCPAP cells promotes migration and invasion. (A and B) Transwell migration and (B and C) Matrigel invasion assays in upregulated PKHD1L1 cells and their corresponding control cells. (B and D) Quantitative results of migration and invasion assays. The stained cells were manually counted from 5 randomly selected fields and normalized for cell proliferation. Mgnification, $\mathrm{x} 40{ }^{*{ }^{* *}} \mathrm{P}<0.01$ and ${ }^{* * *} \mathrm{P}<0.001$ vs. si-NC. PKHD1L1, polycystic kidney and hepatic disease 1-like 1. 
study has demonstrated that the PKHD1L1*I/D genotype is a predictive factor in male longevity (21). Although the gene has been discovered for a long time, the precise mechanism of PKHD1L1 in human cancer remains poorly understood.

In a previous study (31), analysis of 19 matched pairs of thyroid carcinoma tissues and nearby noncancerous tissue revealed that PKHD1L1 expression was downregulated in tumour tissues. The present study aimed to investigate the role of PKHD1L1 in TC. The results demonstrated that the expression levels of PKHD1L1 were significantly downregulated in PTC tumour tissue. In addition, low PKHD1L1 expression in the TCGA cohort was associated with certain clinicopathological features, such as tumour size, distant metastasis, LNM and disease stage. In the validated cohort, tumour size and LNM were associated with low expression of PKHD1L1, which was consistent with TCGA data. Furthermore, PKHD1L1 was identified as a significant predictor of LNM. Loss of function in PKHD1L1 in vitro promoted TC cell proliferation and colony formation compared with control cells. Additionally, PKHD1L1-knockdown TC cells exhibited compromised migratory and invasive capacity compared with control cells.

Certain limitations to the present study should be considered. Firstly, the association between PKHD1L1 and the prognosis of PTC needs to be investigated in large samples. Secondly, rescue experiments such as overexpression of PKHD1L1 in vitro need to be performed. The exact mechanism of the tumourigenic role of PKHD1L1 in PTC needs to be further studied.

In conclusion, the present study investigated the association between PKHD1L1 and PTC LNM, as well as the function of PKHD1L1 in TC in vitro. The results suggested that PKHD1L1 may be a suppressor gene associated with PTC and may be a potential molecular biomarker in the future.

\section{Acknowledgements}

The authors would like to thank Professor Ming-Zhao Xing of Johns Hopkins University School of Medicine (Baltimore, MD, USA) for supplying the cell lines.

\section{Funding}

This study was funded by the National Natural Science Foundation of China (grant no. 81572291), the Natural Science Foundation of Zhejiang province (grant nos. LY17H160053, LGF18H160031, GF18H160071 and LGF18H160032), the Medical and Health Technology Projects of Zhejiang province (grant no. 2017187475) and the Science and Technology Project of Wenzhou (grant no. Y20170030).

\section{Availability of data and materials}

The datasets used and/or analysed during the current study are available from the corresponding author on reasonable request.

\section{Authors' contributions}

$\mathrm{CZ}$ wrote the manuscript. RQ performed the experiments. $\mathrm{CZ}$, $\mathrm{AB}$ and EJX collected and processed the data. $\mathrm{XZ}$ designed the study. All authors read and approved the final manuscript.

\section{Ethics approval and consent to participate}

Ethical approval for this study was obtained from the Ethics Committee of The First Affiliated Hospital of Wenzhou Medical University, Wenzhou, China. Patients signed informed consent forms, and the research protocols for the use of tissues were approved by and conducted in accordance with the ethical standards of the Institutional Review Board of The First Affiliated Hospital of Wenzhou Medical University (approval no. 2012-57).

\section{Patient consent for publication}

Not applicable.

\section{Competing interests}

The authors declare that they have no competing interests.

\section{References}

1. Burns WR and Zeiger MA: Differentiated thyroid cancer. Semin Oncol 37: 557-566, 2010.

2. Siegel RL, Miller KD and Jemal A: Cancer statistics, 2018. CA Cancer J Clin 68: 7-30, 2018.

3. Chen W, Zheng R, Baade PD, Zhang S, Zeng H, Bray F, Jemal A, $\mathrm{Yu}$ XQ and He J: Cancer statistics in China, 2015. CA Cancer J Clin 66: 115-132, 2016.

4. Pellegriti G, Frasca F, Regalbuto C, Squatrito S and Vigneri R: Worldwide increasing incidence of thyroid cancer: Update on epidemiology and risk factors. J Cancer Epidemiol 2013: 965212, 2013.

5. Rahib L, Smith BD, Aizenberg R, Rosenzweig AB, Fleshman JM and Matrisian LM: Projecting cancer incidence and deaths to 2030: The unexpected burden of thyroid, liver, and pancreas cancers in the United States. Cancer Res 74: 2913-2921, 2014.

6. Morris LG, Tuttle RM and Davies L: Changing trends in the incidence of thyroid cancer in the United States. JAMA Otolaryngol Head Neck Surg 142: 709-711, 2016.

7. La Vecchia C, Malvezzi M, Bosetti C, Garavello W, Bertuccio P, Levi F and Negri E: Thyroid cancer mortality and incidence: A global overview. Int J Cancer 136: 2187-2195, 2015.

8. Leboulleux S, Rubino C, Baudin E, Caillou B, Hartl DM, Bidart JM, Travagli JP and Schlumberger M: Prognostic factors for persistent or recurrent disease of papillary thyroid carcinoma with neck lymph node metastases and/or tumor extension beyond the thyroid capsule at initial diagnosis. J Clin Endocrinol Metab 90: 5723-5729, 2005.

9. Parangi S and Suh H: The role of genetic markers in the evaluation and management of thyroid nodules. Surg Clin North Am 94: 515-528, 2014.

10. Xing M: Molecular pathogenesis and mechanisms of thyroid cancer. Nat Rev Cancer 13: 184-199, 2013.

11. Xing $M$ : Genetic alterations in the phosphatidylinositol-3 kinase/Akt pathway in thyroid cancer. Thyroid 20: 697-706, 2010.

12. Xing M: BRAF mutation in thyroid cancer. Endocr Relat Cancer 12: 245-262, 2005.

13. Elisei R, Viola D, Torregrossa L, Giannini R, Romei C, Ugolini C, Molinaro E, Agate L, Biagini A, Lupi C, et al: The $\mathrm{BRAF}(\mathrm{V} 600 \mathrm{E})$ mutation is an independent, poor prognostic factor for the outcome of patients with low-risk intrathyroid papillary thyroid carcinoma: Single-institution results from a large cohort study. J Clin Endocrinol Metab 97: 4390-4398, 2012.

14. Tavares C, Melo M, Cameselle-Teijeiro JM, Soares P and Sobrinho-Simões M: ENDOCRINE TUMOURS: Genetic predictors of thyroid cancer outcome. Eur J Endocrinol 174: R117-R126, 2016.

15. Gustafson S, Zbuk KM, Scacheri C and Eng C: Cowden syndrome. Semin Oncol 34: 428-434, 2007.

16. Morita N, Ikeda Y and Takami H: Clinical significance of p53 protein expression in papillary thyroid carcinoma. World $\mathbf{J}$ Surg 32: 2617-2622, 2008. 
17. Liu X, Bishop J, Shan Y, Pai S, Liu D, Murugan AK, Sun H, El-Naggar AK and Xing M: Highly prevalent TERT promoter mutations in aggressive thyroid cancers. Endocr Relat Cancer 20: 603-610, 2013.

18. Strausberg RL, Feingold EA, Grouse LH, Derge JG, Klausner RD, Collins FS, Wagner L, Shenmen CM, Schuler GD, Altschul SF, et al: Generation and initial analysis of more than 15,000 full-length human and mouse cDNA sequences. Proc Natl Acad Sci USA 99: 16899-16903, 2002.

19. Lian PW, Fu YL, Li A, Dai BZ, Ding ZW, Li L and Wu GQ: Preparation and characterization of a polyclonal antibody against human Fibrocystin-L. Xi Bao Yu Fen Zi Mian Yi Xue Za Zhi 27: 78-81, 2011 (In Chinese).

20. Hogan MC, Griffin MD, Rossetti S, Torres VE, Ward CJ and Harris PC: PKHDL1, a homolog of the autosomal recessive polycystic kidney disease gene, encodes a receptor with inducible T lymphocyte expression. Hum Mol Genet 12: 685-698, 2003.

21. Erdman V V, Karimov DD, Nasibullin TR, Timasheva IR, Tuktarova IA and Mustafina OE: Role of PLAT, PKHD1L1, STK38L and TEAD1 genes Alu-polymorphism for longevity. Adv Gerontol 29: 709-716, 2016 (In Russian).

22. Livak KJ and Schmittgen TD: Analysis of relative gene expression data using real-time quantitative PCR and the 2(-Delta Delta C(T)) method. Methods 25: 402-408, 2001.

23. Edge SB and Compton CC: The American Joint Committee on cancer: The 7th edition of the AJCC cancer staging manual and the future of TNM. Ann Surg Oncol 17: 1471-1474, 2010.

24. Mustafa M, Kuwert T, Weber K, Knesewitsch P, Negele T, Haug A, Linke R, Bartenstein P and Schmidt D: Regional lymph node involvement in T1 papillary thyroid carcinoma: A bicentric prospective SPECT/CT study. Eur J Nucl Med Mol Imaging 37: 1462-1466, 2010.

25. Schneider DF and Chen H: New developments in the diagnosis and treatment of thyroid cancer. CA Cancer J Clin 63: 374-394, 2013.
26. Cho SY, Lee TH, Ku YH, Kim HI, Lee GH and Kim MJ: Central lymph node metastasis in papillary thyroid microcarcinoma can be stratified according to the number, the size of metastatic foci, and the presence of desmoplasia. Surgery 157: 111-118, 2015.

27. Ito Y, Tomoda C, Uruno T, Takamura Y, Miya A, Kobayashi K, Matsuzuka F, Kuma K and Miyauchi A: Ultrasonographically and anatomopathologically detectable node metastases in the lateral compartment as indicators of worse relapse-free survival in patients with papillary thyroid carcinoma. World J Surg 29: 917-920, 2005.

28. Lee YM, Sung TY, Kim WB, Chung KW, Yoon JH and Hong SJ: Risk factors for recurrence in patients with papillary thyroid carcinoma undergoing modified radical neck dissection. Br J Surg 103: 1020-1025, 2016.

29. Sancho JJ, Lennard TW, Paunovic I, Triponez F and Sitges-Serra A: Prophylactic central neck disection in papillary thyroid cancer: A consensus report of the European society of endocrine surgeons (ESES). Langenbecks Arch Surg 399: 155-163, 2014.

30. Comuzzie AG, Cole SA, Laston SL, Voruganti VS, Haack K, Gibbs RA and Butte NF: Novel genetic loci identified for the pathophysiology of childhood obesity in the Hispanic population. PLoS One 7: e51954, 2012.

31. Wang QX, Chen ED, Cai YF, Li Q, Jin YX, Jin WX, Wang YH, Zheng ZC, Xue L, Wang OC and Zhang XH: A panel of four genes accurately differentiates benign from malignant thyroid nodules. J Exp Clin Cancer Res 35: 169, 2016.

This work is licensed under a Creative Commons Attribution-NonCommercial-NoDerivatives 4.0 International (CC BY-NC-ND 4.0) License. 